\title{
Lifestyle modification practice and associated factors among diagnosed hypertensive patients in selected hospitals, South Ethiopia
}

Eyasu Siyum Buda ${ }^{1}$, Lolemo Kelbiso Hanfore ${ }^{2 *}$, Robera Olana Fite ${ }^{2}$ and Alula Seyum Buda ${ }^{3}$

\begin{abstract}
Background: Hypertension is one of the leading causes of disability and death in both developed and developing countries that need urgent strategies to implement interventions that control it. Appropriate lifestyle changes often called non-pharmacological approaches that often overlooked are the corner stone of the prevention and control of hypertension. The aim of this study is to assess the practice of lifestyle modifications and associated factors among diagnosed hypertensive patients in Durame and Nigist Elleni Mohamed Memorial General Hospitals in southern Ethiopia.
\end{abstract}

Methods: Facility-based cross-sectional study was conducted among 205 hypertensive patients in Durame and Nigist Elleni Mohamed Memorial General Hospitals in Sothern Nation and Nationality People Representative (SNNPR), from March 1-30 2016. Simple random sampling was used to select study subjects. Data were entered to Epidata 3.1 and exported to Statistical Package for Social Sciences (SPSS) version 20.0 for analysis. A binary Logistic regression model was fitted to determine independent predictors of lifestyle modifications among hypertensive patients. Adjusted odds ratio at $95 \% \mathrm{Cl}$ was used to declaring the independent effect of each variable on the outcome variable.

Result: The study revealed that only 56(27.3\%) of the patients practiced recommended lifestyle modifications. The study found that age (Adjusted Odds Ratio $[A O R]=0.27,95 \%$ Confidence Interval [Cl]:0.13-0.61), educational status $(\mathrm{AOR}=2.00,95 \% \mathrm{Cl}: 1.33-6.75)$, monthly income $(\mathrm{AOR}=2.46,95 \% \mathrm{Cl}: 1.32-4.63)$, years since diagnosis $(\mathrm{AOR}=2.48,95 \% \mathrm{Cl}$ : 1.32-4.69), and co-morbidity (AOR $=0.28,95 \% \mathrm{Cl}: 0.13-0.61)$ were factors significantly associated with lifestyle modification practice $(p<0.05)$.

Conclusion: Generally, lifestyle modification practices among hypertensive patients were low in this study. Therefore, Patients should be educated on the recommended lifestyle modifications that may help patients to control $f$ their blood pressure.

Keywords: Hypertension, Lifestyle modification, Practice, Hospital, Durame, SNNPR

\footnotetext{
* Correspondence: lolemo2001@gmail.com

${ }^{2}$ College of Health Sciences and Medicine, Department of Nursing, Wolaita

Sodo University, PO Box 138, Wolaita Sodo, Ethiopia

Full list of author information is available at the end of the article
} 


\section{Background}

Hypertension is a major health problem in developed countries and now becoming an increasing important cause of morbidity and mortality in developing countries. Today one in three adults has hypertension. Hypertension is a global public health challenge due to its high prevalence and the associated risk of stroke and cardiovascular diseases in adults. It is estimated to cause 7.5 million deaths worldwide and about $12.8 \%$ of the total annual deaths in SSA [1-3].

The risk factors associated with hypertension are tobacco use, alcohol consumption, obesity, high cholesterol and diabetes mellitus. Tobacco use increases the risk of complications among those with hypertension. In 2008, one billion people were smokers and the global prevalence of obesity has nearly doubled since 1980 [4, 5].

Disease burden is closely related to the average volume of alcohol consumption, and, for every unit of exposure, is strongest in poor people and in those who are marginalized from society [6, 7]. In 2012, about 3.3 million deaths, or $5.9 \%$ of all global deaths, were attributable to alcohol consumption [8]. If inactivity were decreased by $10 \%$ more than 533,000 deaths can be averted. Furthermore, if inactivity is decreased by $25 \%$, more than 1.3 million deaths can be prevented $[9,10]$. Body mass index (BMI) is positively and independently associated with morbidity and mortality from hypertension [11, 12].

Lifestyle modification is the foundation of preventive management in individuals with hypertension. It is recommended as an initial treatment before the start of drug therapy and as an adjunct to medication in those already on drug therapy. Lifestyle modification may facilitate drug step-down and drug withdrawal in highly motivated individuals who achieve and maintain lifestyle changes [13-16]. A lifestyle modification includes weight reduction, salt restriction, and physical activity, smoking cessation and abstaining from alcohol $[17,18]$.

The World Health Organization (WHO) reported that hypertension is responsible for $62 \%$ of cases of cerebrovascular disease and $49 \%$ of cases of ischemic heart disease. In addition, hypertension is the topmost risk factor for death worldwide $[13,19]$. In different studies age, marital status, income, the source from which they get information, the existence of co-morbidity, sex differences and individual's knowledge on hypertension are factors found to influence lifestyle modification practice [20-24].

The balance of energy intake and exercise is an important determinant of hypertension [25]. As suggested WHO, the normal weight for an adult over 18 years is less than or equal to 18.5-24.9. BMI that is greater than this puts one at risk of obesity-related diseases as high blood pressure [26].

Physical Inactivity causes $9 \%$ of premature mortality or more than 5.3 million of the 57 million deaths that occurred worldwide in 2008. If inactivity were not eliminated but decreased instead by 10 or $25 \%$, more than 533,000 and more than 1.3 million deaths, respectively, could be averted every year $[9,10]$.

In Africa, as elsewhere, obesity and sodium intake are risk factors for hypertension. In industrialized societies such as the United States, obesity accounts for $25 \%$ of cases of hypertension. However, due to the relative leanness of Africans, the contribution of obesity to high blood pressure is only around 10\% [27].

In spite of emerging empirical evidence of the efficacy of lifestyle modification in blood pressure control, little is known about the practice of lifestyle modification and associated factors among hypertensive patients in Ethiopia. The study considers that practice of lifestyles and associated factors and their relationships will guide to facilitating for actions for greater practice among the hypertensive patients. Therefore, finding from the study would alert health professionals, government and other stakeholders on lifestyles and factors associated with the practice of these lifestyles to control hypertension.

\section{Methods \\ Study area and period}

The study was conducted in Durame and hosanna towns. Durame is the administrative town of Kembata Tembaro Zone which is found SNNPR and located $285 \mathrm{~km}$ from Addis Ababa and $125 \mathrm{~km}$ from Hawassa which is the capital city of the region. The zone has seven Weredas and three town administration with the estimated population of 857,084 . The durame hospital is the general hospital found in the zone. Hosanna town is also the administrative town for Hadiya zone that is $232 \mathrm{kms}$ from the capital Addis Ababa and $194 \mathrm{~km}$ west of Hawassa. The zone has estimated population of 1,506,733. Nigist Ellen Mohammed memorial General Hospital is a governmental hospital which is found in the Hosanna town. The study was conducted from March 1to April 30, 2016.

\section{Study design}

The facility-based cross-sectional study was conducted in Durame and Nigist Elleni Mohamed memorial general hospitals.

\section{Population}

The source population was all hypertensive patients who were treated in Durame general hospital and Nigist Ellen Mohammed memorial general hospitals. The study population was randomly selected hypertensive patients who came for follow up during the study period. 


\section{Inclusion and exclusion criteria}

All hypertensive patients' age $\geq 18$ years were included in the study. Patients who were severely ill and not able to communicate were excluded from the study.

\section{Sample size determination}

The sample size was determined using a single population proportion by assuming that $50 \%$ proportion of the patients practiced lifestyle modifications with $95 \%$ confidence interval and 5\% margin of error. Using population correction formula and adding $10 \%$ non-response rate the sample size was 210 .

\section{Sampling technique}

Total adult hypertensive follow-up patients are 165 in Durame and 210 in Nigist Ellen Mohammed memorial hospital. Therefore, the total patients registered for follow up in both hospitals were 375 . The sample size was allocated to both hospitals proportionally. All previously, registered 375 patients were included in the sampling frame. Then the study respondents were selected using random sampling technique. The list of patients (sampling frame) was obtained from the registration books of the patients registered for follow up in hospitals and study subjects were selected by lottery method.

\section{Variables of the study}

Dependent variable

The practice of lifestyles modifications.

\section{Independent variables}

Socio-Economic variables; Age, sex, income, marital status, educational status, religion, occupation, ethnicity, residence.

Health profile of the patients; Duration of diagnosis, presence of co-morbidity, family history of hypertension.

Source of information about lifestyles; - medical personnel, media, friends, and family.

Individual factors; knowledge of hypertension.

\section{Data collection instrument}

The questionnaire has socio-Economic, questions related with the source of information about lifestyles, knowledge on hypertension and lifestyles, questions related to lifestyle modification practices and questions about health profile of the patients. The lifestyle modification practices were measured using questionnaires adapted from hypertension self-care practice questions which are recommended by joint national committee on detection, prevention evaluation and treatment of hypertension (JNC7) and WHO STEPS questionnaires [18, 28].

\section{Measurements}

Low-salt diet - ten items were used to assess practices related to eating a healthy diet, avoiding salt while cooking and eating, and avoiding foods high in salt content. A mean score was calculated. Scores of five or better indicate that patients followed the low-salt diet and considered as having good low salt diet practice.

Physical activity - Physical activity was assessed by two items. "How many of the past 7 days did you do at least 30 minutes total of physical activity?" and "how many of the past 7 days did you do a specific exercise activity (such as swimming, walking, or biking) other than what you do around the house or as part of your work?" Responses were summed (Range 0-14) patients who scored eight and above were coded as a having good physical activity practice. All others coded as poor practice.

Smoking - Smoking status was assessed with one item, "How many of the past 7 days did you smoke a cigarette?" Respondents who reported 0 days were considered a nonsmoker.

Weight management - ten items assessed using activities undertaken to manage weight through dietary practices such as reducing portion size and making food substitutions as well as exercising to lose weight. Items assessed agreement with weight management activities during the past 30 days. Response categories ranged from strongly disagree (1) to strongly agree (5). Responses were summed creating a range of scores from 10 to 50. Participants who report that they agreed or strongly agreed with all ten items (score $\geq 40$ ) were considered to have good weight management practice.

Alcohol - Alcohol intake was assessed using 3-item Participants who report not drinking any alcohol in the last 7 days or who indicated that they usually did not drink at all were considered abstainers. All others were considered as not having a good practice of alcohol consumption.

Height was measured using portable stadiometer without participant wearing shoes to the nearest $0.5 \mathrm{~cm}$. reading was taken after the participant was requested to have feet together heals against the back board, knees straight and look straight forward. In addition, weight, to the nearest $0.1 \mathrm{~kg}$. Body mass index (BMI) was calculated from the weight and height. BMI $(\mathrm{kg} / \mathrm{m} 2)$ was categorized as normal weight $(18.5 \leq \mathrm{BMI}<24)$, overweight $(24 \leq \mathrm{BMI}<28)$, and obese (BMI $\geq 28)$ using the using WHO recommendations [28].

\section{Data collection procedures}

Data were collected by two trained diploma nurses and using face to face interview method. One BSc nurse supervisor was assigned to each hospital. The sociodemographic, health profiles of participants, knowledge 
on hypertension, and source of information of the study participants were collected using an interview based structured questionnaire adapted from the WHO manual and reviewing different literatures [28]. Physical characteristics (height and weight) were measured. The lifestyles practices were measured using a tool adapted to the local context from hypertension self-care activity scales [18].

Lifestyle modification practice was measured using physical exercise, low salt diet, alcohol consumption, smoking and weight management practices. The lifestyle modification practice was classified as a 'good practice' and 'poor practice'. Respondents were labeled to have "good" "lifestyle modification practices if they scored above the mean in all recommended lifestyle questions. Weight and height of the patients were measured and BMI was calculated and classified using WHO guideline as normal weight, overweight and obese. Weight and height measurements were taken during data collection.

\section{Data quality control}

The questionnaire was prepared in English then translated into Amharic language and was back translated into the English language by another person to check its consistency.

The questionnaire was pre-tested in $5 \%$ of total eligible patients in Butajira hospital for their accuracy and consistency prior to actual data collection. Furthermore, the supervisor and the investigator were given feedback and corrections on daily basis to the data collectors. Completion, accuracy, and clarity of the collected data were checked carefully on a regular basis. The data was carefully entered and cleaned before the beginning of the analysis.

\section{Data processing and analysis}

After collection, data were checked for completeness and were entered into Epidata 3.1 version and exported to SPSS 20.0 version for further analysis. Descriptive statistical analysis such as Proportion, frequency distribution, means, and the measure of dispersion was used to describe data and analytical statistics including bivariate and multivariable logistic regression analysis was done. Bivariate logistic regression was done to examine the association between dependent and independent variables. After running bivariate logistic regressions, all variables with $p<0.25$ was considered as a candidate for the final model and corresponding $p$-value of $<0.05$ was considered as statistically significant. Adjusted odds ratio at $95 \%$ CI was considered to declare the independent effect of independents variables on the outcome. Finally, results were presented using charts and tables.

\section{Operational definitions}

Good lifestyle modification Practice: when patients respond the mean or above the mean score on practice questions.

Poor lifestyle modification practice: when patients respond below the mean score on practice questions.

\section{Result}

\section{Socio-demographic characteristics of study subjects}

Out of 210 study participants, 205(97.5\%) participated in the study. More than half $105(51.2 \%)$ of them were females. The mean age of respondents was 53.9 (SD \pm 9.64 years). About two-third 136(66.3\%) of participants were married. Regarding the educational status of subjects, $118(42.4 \%)$ has no formal education. Concerning their employment status, 63(30.7\%) were government employees. 105(51.7\%) were Protestants in their religion and $102(41 \%)$ of the study, subjects were Hadiya in Ethnicity. Average monthly income for $48(23.4 \%)$ of them was less than 500 ETB (Table 1).

\section{Lifestyle modification practice}

The mean score for lifestyle modification practice was 40 (SD \pm 14.36 ). Only $56(27.3 \%)$ patients practiced recommended lifestyle modification. The mean $(+\mathrm{SD})$ score for physical activity was $4.46( \pm 3.45)$ with the maximum score of 14 . Only $33(16.1 \%)$ practiced physical activity for $30 \mathrm{~min}$ per day. The mean $(+\mathrm{SD})$ score of weight management practice of the patients were 29.36( \pm 13.43 ) with the maximum score of 50. Eighty-six (41.9\%) had good weight management practice. The mean $( \pm S D)$ score for low salt diet was $4.59( \pm 2.03)$. From the patients, 118 (57.5\%) practiced recommended low diet salt. One hundred eighty (87.9\%) did not drink alcohol in the last 7 days. One hundred eighty-seven (91.2\%) were not a smoker (Fig. 1 and Table 2).

\section{Health profile related, individual related and source of information related factors}

From the patients who had basic knowledge about hypertension $23(25 \%)$ practiced good lifestyle modification and those who were in treatment for 5 to 10 years (13.6\%) practiced good lifestyle modification. From those who had a family history of hypertension 20(31.7\%) practiced good lifestyle modification. From those who were informed by health professionals $31(35.2 \%)$ practiced good lifestyle modification. Twenty three (25.8\%) of patients with co-morbidity practiced good lifestyle modification (Table 3).

\section{Factors associated with lifestyle modification practice among hypertensive patients}

Age, Marital status, educational status, monthly income, duration of diagnosis, had information about lifestyle, 
Table 1 Socio-demographic characteristics of hypertensive patients in Durame and Nigist Elleni Mohamed Memorial General Hospitals, SNNPR, May $2016(\mathrm{~N}=205)$

\begin{tabular}{|c|c|c|}
\hline Variables & Frequency & Percent (\%) \\
\hline \multicolumn{3}{|l|}{ Age } \\
\hline$<65$ years & 174 & 84.9 \\
\hline$>=65$ years & 12 & 15.1 \\
\hline \multicolumn{3}{|l|}{ Sex } \\
\hline Male & 100 & 48.8 \\
\hline Female & 105 & 51.2 \\
\hline \multicolumn{3}{|l|}{ Marital status } \\
\hline Married & 136 & 66.3 \\
\hline Single & 24 & 11.7 \\
\hline Divorced & 15 & 7.3 \\
\hline Widowed & 30 & 14.6 \\
\hline \multicolumn{3}{|l|}{ Educational status } \\
\hline Formal education & 87 & 57.6 \\
\hline No formal education & 118 & 42.4 \\
\hline \multicolumn{3}{|l|}{ Employment status } \\
\hline Government employee & 63 & 30.7 \\
\hline Private employee & 63 & 30.7 \\
\hline Merchant & 36 & 17.6 \\
\hline Housewife & 23 & 11.2 \\
\hline Daily laborer & 14 & 6.8 \\
\hline Retired & 6 & 2.9 \\
\hline \multicolumn{3}{|l|}{ Religion } \\
\hline Orthodox & 65 & 31.7 \\
\hline Protestant & 105 & 51.2 \\
\hline Muslim & 10 & 4.9 \\
\hline Catholic & 25 & 12.2 \\
\hline \multicolumn{3}{|l|}{ Ethnicity } \\
\hline Hadiya & 102 & 49.8 \\
\hline Kembata & 57 & 27.8 \\
\hline Gurage & 21 & 10.2 \\
\hline Wolaita & 16 & 7.8 \\
\hline others & 9 & 4.4 \\
\hline \multicolumn{3}{|l|}{ Average monthly Income } \\
\hline$<500$ ETB & 48 & 23.4 \\
\hline 500-999 ЕТВ & 61 & 29.8 \\
\hline$>=1000 \mathrm{ETB}$ & 96 & 46.8 \\
\hline
\end{tabular}

the source of information, co-morbidity status were entered into the final model. According to the result of the multivariable analysis, Age, duration since diagnosis, average monthly income, educational status, and comorbidity were independent predictors of good lifestyle modification practice among hypertensive patients.

\section{Life Style Modification Practice}

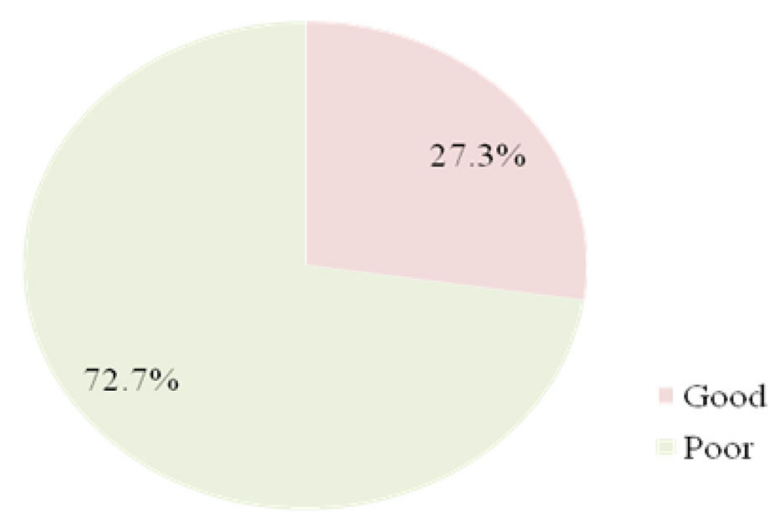

Fig. 1 Life style modification practice among hypertensive patients in Durame and Nigist Elleni Mohamed Memorial General Hospitals, SNNP, 2016 $(N=205)$

Patients aged greater than 65 years were $72 \%$ less likely to have good lifestyle modification practice (AOR $=0.28$, 95\% CI: 0.13-0.61) than patients with below 65 years. On the other hand, hypertensive patients with income of 1000 ETB were 2.4 times more likely to practice good lifestyle modification $(\mathrm{AOR}=2.38,95 \%$ CI:1.15-5.57) as compared to patients with income of less than 500ETB.

Patients without formal education were 2 times more likely practice good lifestyle modification $(\mathrm{AOR}=2.00$, 95\% CI: 1.33-6.75) as compared to those who had formal education.

Table 2 Life style modification practices among hypertensive patients in Durame and Nigist Elleni Mohamed Memorial General Hospitals, SNNPR, May $2016(N=205)$

\begin{tabular}{lcc}
\hline Variables & Frequency & Percent \\
\hline Practice physical activity for thirty minutes per day $(N=205)$ \\
Yes & 33 & 16.1 \\
No & 172 & 73.9 \\
Weight management practice $(N=147)$ & \\
Good & 86 & 41.9 \\
Bad & 61 & 58.1 \\
Practice recommended low salt diet $(N=205)$ & \\
Yes & 118 & 57.5 \\
No & 87 & 42.5 \\
Alcohol consumption $(N=205)$ & \\
Yes & 180 & 87.9 \\
No & 25 & 12.1 \\
Smoking status $(N=205)$ & & \\
Yes & 18 & 10.8 \\
No & 187 & 91.2 \\
\hline
\end{tabular}


Table 3 Health profile related, individual related and source of information related factors among hypertensive patients in Durame and Nigist Elleni Mohamed Memorial General Hospitals, SNNP, 2016(N=205)

\begin{tabular}{|c|c|c|}
\hline \multirow[t]{3}{*}{ Variables } & \multicolumn{2}{|c|}{ Lifestyle Modification Practice } \\
\hline & Good & Poor \\
\hline & N (\%) & N (\%) \\
\hline \multicolumn{3}{|c|}{ Knowledgeable about Hypertension } \\
\hline Yes & $23(25.0)$ & $68(75)$ \\
\hline No & $33(29.2)$ & $80(70.8)$ \\
\hline \multicolumn{3}{|l|}{ Duration since diagnosis } \\
\hline$<2$ years & $6(13.6)$ & $38(86.4)$ \\
\hline $2-5$ years & $30(33.3)$ & $60(66.7)$ \\
\hline $5-10$ years & 19(28.4) & 48(71.6) \\
\hline$>10$ years & $1(25.0)$ & $3(75.0)$ \\
\hline \multicolumn{3}{|c|}{ Family history of Hypertension } \\
\hline Yes & $20(31.7)$ & $43(68.3)$ \\
\hline No & $36(25.4)$ & 106(74.6) \\
\hline \multicolumn{3}{|c|}{ Hear information about lifestyles } \\
\hline Yes & $39(33.1)$ & $79(66.9)$ \\
\hline No & 17(19.5) & $70(80.5)$ \\
\hline \multicolumn{3}{|l|}{ Source of information } \\
\hline Health professionals & $31(35.2)$ & $57(64.8)$ \\
\hline Different medias & $6(33.3)$ & $12(66.7)$ \\
\hline Family and friends & $3(21.4)$ & 11(78.6) \\
\hline \multicolumn{3}{|l|}{ Co-morbidity } \\
\hline Yes & 23(25.8) & $66(74.2)$ \\
\hline No & $33(28.4)$ & 83(71.6) \\
\hline
\end{tabular}

Individuals with five to 10 years treatment duration were 2.5 times more likely to practice lifestyle modification $(\mathrm{AOR}=2.48,95 \% \mathrm{CI}: 1.32-4.69)$ as compared to those on treatment for less 2 years treatment. On the other hand, patients who were with co-morbidity were $72 \%$ less likely to practice good lifestyle modification ( $\mathrm{AOR}=0.28,95 \% \mathrm{CI}: 0.13-0.61)$ as compared to those without co-morbidity (Table 4 ).

\section{Discussion}

This study was conducted with intention to assess lifestyle modification practices and associated factors among hypertensive patients. Control of hypertension represents a major challenge and requires attention to both pharmacological and non-pharmacological treatment. Measurement of the rates of lifestyle practices and medications together with the identification of its determinants is of ultimate importance for the design effective strategies to control hypertension. The study revealed that 92 (44.9\%) had good basic knowledge regarding hypertension which is low compared with a study done in Jimma showed $67.7 \%$ participants have good knowledge regarding hypertension [29]. however, the finding of a study in Egypt supports with the current finding [30].

Eighty-eight (73.2\%) reported their source of information about recommended lifestyle were health professionals. This is supported by finding from study in Nigeria [17].

From the participants (92.2\%) were non-smokers and $(89.7 \%)$ were abstained from alcohol drinking. This is supported by study finding [20]. This could be due to social and cultural practices that discourage alcohol drinking and smoking.

Adequate physical activity has been shown to have many health-promoting effects and has a direct role in reducing blood pressure [31, 32]. In this study very fewer patients $56(27.7 \%)$ practiced lifestyle modification. This finding is lower than a study done in china in which (70\%) of participants practice lifestyle modification and higher than from study done in Saudi Arabia [21, 33]. This might be due to difference educational back ground of patients and level of awareness about lifestyle modification and its advantages. It also might be due to patients relay only on medication considering lifestyle modification has no effect on their blood pressure.

Among lifestyles modifications only (16.1\%) of the participants practice regular exercise $30 \mathrm{~min}$ per day for most of the days in a week, which is lower than (89\%) and $(43.7 \%)$ patients physically active in studies done India and Addis Ababa respectively [20, 34]. A possible explanation could be lack of organized setups that are favorable for exercise. Another possible explanation could be poor knowledge on the importance of physical activity in the management of hypertension. A similar study done in Saudi Arabia showed that only (11.1\%) of patients practiced physical activity most of the days in a week. Another study was done in the USA in African Americans also showed the majority of the patients practiced physical activity that is higher than this study's finding [35].

The mean $(+\mathrm{SD})$ practice score of low salt diet was $4.59( \pm 2.03)$. One hundred eighteen subjects $(57.5 \%)$ have poor low salt diet practice. This finding was higher than a study done in Saudi [21] but this finding is lower than the finding of a study done in hypertensive patients in Jimma university specialized hospital (Ethiopia) which showed $80 \%$ of hypertensive patient avoid salt in their diet. In addition, a study done in the United States showed low salt diet practices among African Americans [35]. This may be due to the socio-cultural practice of the community and poor knowledge about the effect of high salt diet in blood pressure control. In addition, it could be due to the intention of individuals to make the food tastier by adding salt that is common in Africa [29]. 
Table 4 Predicators of lifestyle modification practice among hypertensive patients in Durame and Nigist Elleni Mohamed Memorial General Hospitals, SNNP, 2016(N = 205)

\begin{tabular}{|c|c|c|c|c|}
\hline \multirow[t]{3}{*}{ Variables } & \multicolumn{2}{|c|}{ Lifestyle modification practice } & \multirow[t]{3}{*}{ COR $(95 \% \mathrm{Cl})$} & \multirow[t]{3}{*}{ AOR $(95 \% \mathrm{Cl})$} \\
\hline & Good & Poor & & \\
\hline & N (\%) & N (\%) & & \\
\hline \multicolumn{5}{|l|}{ Age } \\
\hline$<65$ yrs & $45(25.9)$ & $129(74.1)$ & & 1 \\
\hline$>=65 \mathrm{yrs}$ & $11(5.4)$ & 20(9.8) & $1.58(0.70-3.54)$ & $0.27(0.13-0.61)^{*}$ \\
\hline \multicolumn{5}{|l|}{ Marital status } \\
\hline Married & $34(25.0)$ & 102(75.0) & & 1 \\
\hline Single & $10(41.7)$ & $14(58.3)$ & $2.14(0.45-2.68)$ & $1.08(0.45-2.58)$ \\
\hline Divorced & $4(26.7)$ & $11(73.3)$ & $0.92(0.27-3.06)$ & $1.09(0.22-1.78)$ \\
\hline Widowed & $8(26.7)$ & $22(73.3)$ & $1.09(1.04-4.06)$ & $1.33(0.60-2.94)$ \\
\hline \multicolumn{5}{|l|}{ Educational status } \\
\hline No Formal Education & $38(32.2)$ & $80(67.8)$ & $1.82(1.01-3.48)$ & $2.00(1.33-6.75)$ \\
\hline Formal Education & $18(20.7)$ & $69(79.3)$ & & 1 \\
\hline \multicolumn{5}{|l|}{ Monthly income } \\
\hline$<500$ ETB & $8(16.7)$ & $40(83.3)$ & & 1 \\
\hline 500-999ETB & $17(27.9)$ & $44(72.1)$ & $0.52(0.20-1.33)$ & $1.23(0.61-2.49)$ \\
\hline$>1000 \mathrm{ETB}$ & $31(32.3)$ & $65(67.7)$ & $2.38(1.15-5.70)$ & $2.41(1.32-4.63)^{* *}$ \\
\hline \multicolumn{5}{|l|}{ Duration of diagnosis } \\
\hline$<2$ years & 19(28.4) & $48(71.6)$ & & 1 \\
\hline $2-5$ years & $30(33.3)$ & $60(66.7)$ & $3.17(0.38-6.58)$ & $3.81(1.27-6.51)$ \\
\hline $5-10$ years & $6(13.6)$ & $38(86.4)$ & $2.51(1.25-6.89)$ & $2.48(1.32-4.64)^{*}$ \\
\hline$>10$ years & $1(25.0)$ & $3(75.0)$ & $2.11(0.12-12.14)$ & $1.19(0.12-12.14)$ \\
\hline \multicolumn{5}{|c|}{ Hear information about lifestyles } \\
\hline Yes & 39(33.1) & $79(66.9)$ & & 1 \\
\hline No & $17(19.5)$ & $70(80.5)$ & $0.49(0.25-0.95)$ & $0.64(0.29-1.38)$ \\
\hline \multicolumn{5}{|l|}{ Source of information } \\
\hline Health professionals & $31(35.2)$ & $57(64.8)$ & & 1 \\
\hline Different Medias & $6(33.3)$ & $12(66.7)$ & $0.91(0.53-12.53)$ & $2.64(0.77-9.09)$ \\
\hline Family and friends & $3(21.4)$ & $11(78.6)$ & $1.99(0.52-27.72)$ & $4.44(0.81-27.72)$ \\
\hline \multicolumn{5}{|l|}{ Co-morbidity } \\
\hline Yes & $23(25.8)$ & $66(74.2)$ & $0.87(0.03-0.93)$ & $0.28(0.13-0.61)^{*}$ \\
\hline No & $33(28.4)$ & 83(71.6) & & 1 \\
\hline
\end{tabular}

* Significant at $p$-value $<0.05,{ }^{*}$ Significant at $p$-value $<0.001$

The mean $(+\mathrm{SD})$ of weight management practice of study subjects was $29.36( \pm 13.43)$ with the maximum score of 50. Eighty-six (41.9\%) only have good weight management practice. The finding is in consistence with study done in the United States. This finding was also supported by study in Saudi and Nigeria [21, 35, 36].

Higher age ( $>65$ years) was significantly associated with lifestyle modification practice Patients. Age Above 65 years old was $73 \%$ less likely to practice lifestyle modification $(\mathrm{AOR}=0.27,95 \% \mathrm{CI}: 0.13-0.61)$. This is in line with the study done in China and Nigeria [22, 33].
This could be due to older persons have less education, decreased cognitive function and have more comorbidities which may inhibit the practice of the lifestyles. Another explanation might be younger patients were more likely to be educated, eager to control their blood pressure by practicing the lifestyle modification.

The results of the analysis showed patients without formal education were 2 times more likely to practice lifestyle modification $(\mathrm{AOR}=2.0095 \% \mathrm{CI}$ : 1.33-6.75) as compared to those who attended formal education. This is inconsistent with the study done Nigeria and 
Botswana in which as educational status increase practice of lifestyle modification was higher [22, 23].

Average monthly income was significantly associated with lifestyle modification practice. Participants with a monthly income of more than 1000ETB were 2.4 times more likely to practice lifestyle modification $(\mathrm{AOR}=2.41,95 \% \mathrm{CI}: 1.32-4.63)$. This is supported by the finding from the study in Saudi in which level of monthly income was highly significantly associated with lifestyle modification practice [21]. This could be due to individuals with low income could face to manage their diet properly and could not get favorable setups to do physical exercise. This also might be due to cultural differences that influence the living style of the individuals.

Patients on treatment for 5-10 years were 2.48 times $(\mathrm{AOR}=2.48$ 95\%CI: 1.32-4.64) more likely to practice lifestyle modification as compared to those patients who were in treatment for less than 2 years. This finding is supported by different studies that show patients on longer duration of treatment had good lifestyle modification practice $[21,36]$. This might be due to continued counseling' and health education.

Patient with co-morbidity was $72 \%$ less likely to practice lifestyle modification practices $(\mathrm{AOR}=0.28$, 95\%CI: 0.13-0.61) compared to patients without comorbidity. Hypertension with the presence of other co-morbidity is very difficult to control. Comorbidities can worsen the conditions of the patient and make them unable to adhere to practice lifestyle changes [34]. This finding is consistent with the study done in India and Ethiopia (Addis Ababa) that showed patients without co-morbidity were more likely to practice lifestyle modification [20, 34]. This difference could be due to the difference in living standard and cultural differences. In addition, it might be due to difference educational status. Peoples in an urban area are more educated and might have awareness about their blood pressure.

The main limitation of this study is lack of adequate similar studies in our country, which made comparison difficult for the lifestyle changes. In addition, the data was self-report from the participants; there may be the denial of poor practices from the respondents, which affects the result of the study.

\section{Conclusion}

This study revealed lifestyle modification practice is low among the hypertensive patients. Lifestyle modification through changes in eating patterns, abstaining from alcohol, weight management, smoking cessation and regular physical activity forms part of important and effective treatment strategies for hypertension. Regardless of other indicated treatments, all hypertensive patients who need to control their blood pressure should be given advice and support to achieve and maintain lifestyle practices. Age, Duration of the hypertension diagnosis, educational status, average monthly income, and comorbidity were factors significantly associated with lifestyle modification practice.

\section{Abbreviations \\ AOD: Adjusted odds ratio; Cl: Confidence interval; IRB: Institutional Review Board; SPSS: Statistical Package for Social Sciences}

\section{Acknowledgements}

We would like to thank Jimma University for providing an ethical clearance for this research. We also thank the health managers and the patients who have been very cooperative during data collection.

\section{Funding}

There no financial support from any organization.

\section{Availability of data and materials}

The spreadsheet data supporting the findings of this is available at the hands of the corresponding author which can be delivered to the journal based on request at any time.

\section{Authors' contributions}

LKH, ESB, ROF and ASB conceptualized, designed the study, analyzed, interpreted the data, drafted the manuscript and critically reviewed the manuscript. All the authors read and approved the manuscript.

\section{Ethics approval and consent to participate}

Ethical approval was obtained from the Institutional Review Board (IRB) of Jimma University, College of Health Sciences. The purpose of the study was explained to the study participants at the time of data collection and verbal consent was secured from each participant before the start of data collection. Confidentiality was ensured by not including names or other identifiers in the data collection tool. The right of the participants to refuse participation or not to answer any of the questions was respected.

Consent for publication

Not applicable.

\section{Competing interests}

The authors declare that they have no competing interests.

\section{Publisher's Note}

Springer Nature remains neutral with regard to jurisdictional claims in published maps and institutional affiliations.

\section{Author details}

${ }^{1}$ Doyogena Woreda Health Office, Medical Services Core Process Coordinator, SNNPR, Doyogena, Ethiopia. ${ }^{2}$ College of Health Sciences and Medicine, Department of Nursing, Wolaita Sodo University, PO Box 138, Wolaita Sodo, Ethiopia. ${ }^{3}$ Faculty of Health Sciences, Department of Nursing, Wachemo University, Hosaena, Ethiopia.

Received: 14 July 2017 Accepted: 17 November 2017 Published online: 04 December 2017

References

1. Iyalomhe GBS, Lyalomhe SI. Hypertension-related knowledge attitude and lifestyle practices among hypertensive patients in sub-urban Nigerian community. J Public Health Epidemiol. 2010;2(4):71-7.

2. Awoke A, Awoke T, Alemu S, Megabiaw B. Prevalence and associated factors of hypertension among adults in Gondar, Northwest Ethiopia: a community based cross-sectional study. BMC Cardiovasc Disord. 2012; 12:113

3. World Health Organization. Preventing chronic diseases: a vital investment In: Vita-Finzi L, editor. . Geneva: World Health Organization; 2005. 
4. World Health Organization. Burden: mortality, morbidity and risk factors. In Ala A, editor. Global status report on noncommunicable diseases 2010. Geneva: World Health Organization; 2010. p. 9-31.

5. Global action plan for the prevention and control of noncommunicable diseases 2013-2020. Geneva: World Health Organization; 2013.

6. World Health Organization; 2013. World Health Organization. Global Health risks: mortality and burden of disease attributable to selected major risks. Geneva: World Health Organization; 2009.

7. Rehm J, Mathers C, Popova S, Thavorncharoensap M, Teerawattananon Y, Patra J. Global burden of disease and injury and economic cost attributable to alcohol use and alcohol-use disorders. Lancet. 2009;373(9682):2223-33.

8. World Health Organization. Health consequences. In: Poznyak V, Rekve D, editors. Global status report on alcohol and health-2014. Geneva: World Health Organization; 2014. p. 45-57.

9. Allender S, Foster C, Scarborough P, Rayner M. The burden of physical activity-related ill health in the UK. J Epidemiol Community Health. 2007; 61(4):344-8.

10. Lee IM, Shiroma EJ, Lobelo F, Puska P, Blair SN, Katzmarzyk PT, Lancet Physical Activity Series Working Group. Effect of physical inactivity on major non-communicable diseases worldwide: an analysis of burden of disease and life expectancy. Lancet. 2012;380(9838):219-29.

11. Ng M, Fleming T, Robinson M, Thomson B, Graetz N, Margono C, et al. Global, regional, and national prevalence of overweight and obesity in children and adults during 1980-2013: a systematic analysis for the global burden of disease study 2013. Lancet. 2014;384(9945):766-81.

12. Tesfaye F, Nawi NG, Van Minh H, Byass P, Berhane $Y$, Bonita R, et al. Association between body mass index and blood pressure across three populations in Africa and Asia. J Hum Hypertens. 2007;21(1):28-37.

13. Ghezelbash S, Ghorbani A. Lifestyle modification and hypertension prevention. ARYA Atherosclerosis J. 2012;8:S202-7.

14. Verma P, Manushi S, Ratan KS. Assessment of extent of lifestyle modification among diagnosed patients of hypertension attending tertiary care hospital. Int J Med Health Sci. 2015;4(2):196-201.

15. Hareri HA, Gedefaw M, Simeng B. Assessment of prevalence and associated factors of adherence to antihypertensive agents among adults on follow up in Adama Referal hospital, east Shoa, Ethiopia-cross sectional study. Int J Curr Microbilol App Sci. 2014;3(1):760-70.

16. Viera AJ, Lingley K, Esserman D. Effects of labeling patients as prehypertensive. J Am Board Fam Med. 2010;23(5):571-83.

17. Ike SO, Aniebue PN, Aniebue UU. Knowledge, perceptions and practices of lifestyle-modification measures among adult hypertensives in Nigeria. Trans R Soc Trop Med. 2010;104(1):55-60.

18. US Department of Health and Human Services. The seventh report of the joint National Committee on prevention, detection, evaluation, and treatment of high blood pressure. Atlanta: U.S. Department of Health and Human Services, Centers for Disease Control and Prevention, National Center for Chronic Disease Prevention and Health Promotion; 2004.

19. Al-Gelban KS, Khan MY, Al-Khaldi YM, Mahfouz AA, Abdelmoneim I, Daffalla $A$, et al. Adherence of primary health care physicians to hypertension management guidelines in the Aseer region of Saudi Arabia. Saudi J Kidney Dis Transpl. 2011;22(5):941-8.

20. Durai $V$, Muthuthandavan AR. Knowledge and practice on lifestyle modifications among males with hypertension. Indian J Community Health. 2015;27(1):143-9.

21. Elbur Al. Level of adherence to lifestyle changes and medications among male hypertensive patients in two hospitals in Taif; Kingdom of Saudi Arabia. Int J Pharm Pharm Sci. 2015;7(4):168-72.

22. Okwuonu CG, Ojimadu NE, Okaka El, Akemokwe FM. Patient-related barriers to hypertension control in a Nigerian population. Int J Gen Med. 2014;7:345-53.

23. Zungu LI, Djumbe FR,Setswe KG. Knowledge and lifestyle practices of hypertensive patients attending a primary health care clinic in Botswana. AJPHERD 2013:123-38.

24. Marfo AFA, Owusu-Daaku FT, Addo MO, Saana II. Ghanaian hypertensive patients understanding of their medicines and lifestyle modification for managing hypertension.Int. J Pharm Pharm Sci. 2014;6(4):165-70.

25. Balasi LR, Paryad E, Moghaddam SB. Nursing students' attitudes towards coronary artery disease prevention. JNMS. 2014;19(2):40-5.

26. Cooper RS, Rotimi CN, Kaufman JS, Muna WF, Mensah GA. Hypertension treatment and control in sub-Saharan Africa: the epidemiological basis for policy. BMJ. 1998;316(7131):614-7.
27. Jones DW, Kim JS, Andrew ME, Kim SJ, Hong YP. Body mass index and blood pressure in Korean men and women: the Korean National Blood Pressure Survey. J Hypertens. 1994;12(12):1433-7.

28. World Health Organization. The WHO STEPwise approach to surveillance of noncommunicable diseases (STEPS). Geneva: World Health Organization; 2003.

29. Tesema S, Disasa B, Kebamo S, Kadi E. Knowledge, attitude and practice regarding lifestyle modification of hypertensive patients at Jimma University specialized hospital, Ethiopia. Prim Health Care. 2016;6(1):218-21.

30. Abd El-Hay SA, El Mezayen SE. Knowledge and perception related to hypertension, lifestyle modification behavior and challenges that facing hypertensive patient. IOSR-JNHS. 2015;4(6):15-26.

31. Joint Health Surveys Unit. Risk factors for cardiovascular disease. In: Sporston K, Primatesta P, editors. Health survey for England. London: The Stationery Office; 2004

32. Rodgers A, Ezzati M, Vander Hoorn S, Lopez AD, Lin RB, CJL M, et al: Distribution of major health risks: findings from the global burden of disease study. PLoS Med. 2004;1(1):e27.

33. $\mathrm{Hu} \mathrm{H}, \mathrm{Li} \mathrm{G}$, Arao T. Prevalence rates of self-care behaviors and related factors in a rural hypertension population: a questionnaire survey. Int J Hypertens. 2013;2013:526949.

34. Hareri HA, Abebe M, Asefaw T. Assessments of adherence to hypertension managements and its influencing factors among hypertensive patients attending black lion hospital chronic follow up unit, Addis Ababa, Ethiopia-a cross-sectional study. Int J Pharm Sci Res. 2013;4(3):1086-95.

35. Warren-Findlow J, Seymour RB. Prevalence rates of hypertension self-care activities among African Americans. J Natl Med Assoc. 2011;103(5):503-12.

36. Okwuonu CG, Emmanuel Cl, Ojimadu NE. Perception and practice of lifestyle modification in the management of hypertension among hypertensive in south-east Nigeria. Int J Med Biomed Res. 2014;3(2):121-31.

\section{Submit your next manuscript to BioMed Central and we will help you at every step:}

- We accept pre-submission inquiries

- Our selector tool helps you to find the most relevant journal

- We provide round the clock customer support

- Convenient online submission

- Thorough peer review

- Inclusion in PubMed and all major indexing services

- Maximum visibility for your research

Submit your manuscript at www.biomedcentral.com/submit
) Biomed Central 